\title{
Acceptance of homegrown enterprise resource planning (ERP) systems in Ethiopia
}

\author{
Mekonnen Wagaw* ${ }^{*}$
}

*Correspondence:

monalitha@gmail.com Faculty of Computing, Bahir Dar Institute of Technology, Bahir Dar University, Bahir Dar, Ethiopia

\begin{abstract}
In the current competitive global market, organizations are implementing information and communication technology (ICT) that could add value to their products, processes, and satisfaction of their users. The adoption, implementation and use of homegrown enterprise resource planning (ERP) systems is one of these mechanisms being globally used for recording, processing, storing, and exchanging organizational information anytime anywhere. Although organizations have been utilizing ERP systems, the acceptance of homegrown ERP systems is given less attention as compared to commercial off-the shelf (COTS) software. Hence, this research studied factors that determine acceptance of homegrown ERP through the extension of unified theory of acceptance and use of technology (UTAUT) model. The finding revealed that performance expectancy, effort expectancy, social influence, competitive advantage, cost effectiveness, and facilitations functions are determinants of homegrown ERP system acceptance in Ethiopia. Moreover, experience and voluntariness are found to be significant moderators of the study.
\end{abstract}

Keywords: UTAUT, TAM, ERP, Adoption, Technology acceptance, ICT acceptance

\section{Background}

Although organizations have been performing every operation manually, the expanding nature of organizational activities and globalization is enabling them to adopt, implement, and use information and communication technology (ICT). ICT has been enabling organizations globally to carryout operations in an effective and efficient manner. Currently, exchange of information pertaining products, services, processes, manufacturing is being facilitated with the aid of ICT. Organizations have been using both commercial off-the-shelf and bespoke/custom or tailored/homegrown software to support their organizational operations and perform in an efficient manner. Even though these two groups of software have their own advantages and disadvantages, most researches show that the advantage of bespoke software is much more preferable for enterprise resource planning (ERP) purposes than commercial off-the-shelf software.

Since 1990s, firms throughout the world have been adopting and using enterprise resource planning (ERP) systems to have a standardized and organized information system (Rajagopal 2002) that could enable them to manage their, particularly, financial transactions or accounting, manufacturing, supply chain, human resource, and inventory systems in an integrated manner. ERP systems are an integrated software that handles

(c) The Author(s) 2017. This article is distributed under the terms of the Creative Commons Attribution 4.0 International License (http://creativecommons.org/licenses/by/4.0/), which permits unrestricted use, distribution, and reproduction in any medium, provided you give appropriate credit to the original author(s) and the source, provide a link to the Creative Commons license, and indicate if changes were made. 
core organizational processes using a common database system. According to Zhelyazkov (2012), "ERP systems are comprehensive software packages that seek to integrate the complete range of a business process and functions in order to present a holistic view of the business from a single information and information technology architecture".

Since ERP systems could create a unified enterprise that handles all departmental functions using a common database which handles all business transactions, such systems enhance interdepartmental coordination and cooperation (AlQashami and Heba 2015; Ehie and Madsen 2005; Bingi et al. 1999). Moreover, the continuous changes in market, process, and products, firms have been progressively adopting and using ERP systems investing millions of dollars throughout the world (Stratman and Roth 2002). In 2002 and 2010 the global expenditure on such systems would be $\$ 72$ billion and $\$ 1$ trillion respectively. By 2016, the global revenue for ERP systems was projected to reach \$32.6 (Statistica 2016; Heald and Kelly 1998). However, many of such system implementations failed and the realization of ERP's potential benefits was rare (Stratman and Roth 2002; Umble et al. 2003). This is basically created when there is mismatch or incompatibility between organizational requirements and purchased ERP packages in terms of data, function, and output (Umble et al. 2003; Markus and Cornelius 2000; Kien and Soh 2003; Lucas et al. 1988). "The greatest enterprise system implementation failures seem to occur when the new technologies capabilities and needs are mismatched with the organizations existing business processes and procedures" (Umble et al. 2003; Soh et al. 2000).

Although COTS can be purchased and used without taking longer time, they might not go with the rules, regulations and procedures of an organization. Such systems are developed per the requirements organizational needs so as to fit with the intent of the organization without changing any organizational rules and regulations. Moreover, such systems are flexible and could be modified as changes occur.

Hence, organizations prefer homegrown ERP systems that are developed per organizational requirements so as to fit their business process and procedures.

Even though homegrown ERP systems are much more recommend especially for developing countries, organizations in Ethiopia have been reluctant to accept homegrown ERP systems. Moreover, the issue is under researched particularly in the context of developing countries like Ethiopia. Hence, this empirical study was conducted having the objective of identifying determinants that affect acceptance of homegrown ERP systems in Ethiopia so as to support decision makers, consultants, researchers and academia. In order to achieve this objective, the following research questions (1) what are the factors that affect homegrown ERP systems' acceptance in Ethiopian context? (2) to what extent do these factors affect homegrown ERP systems' acceptance in Ethiopia? (3) what is the status of homegrown ERP systems' acceptance in Ethiopia?

\section{Research model\& hypotheses}

In relation to adoption or acceptance of information technologies, several researchers suggested their own theories that are still being used in information systems studies too. The Unified Technology Acceptance Theory (UTAUT) was developed by Venkatesh et al. in (2003). The unified model was developed on the basis of theoretical and empirical similarities of eight previously developed models. These theories were: technology acceptance model (TAM), motivational model (MM), theory of reasoned action (TRA), 
theory of planned behavior (TPB), model of PC utilization (MPCU), innovation diffusion theory (IDT), social cognitive theory (SCT), and theory of reasoned action (TRA).

The comprehensiveness, validity and reliability of the UTAUT model has motivated the author of this study to adopt and validate it in the context of homegrown ERP in Ethiopia. This theory states that "performance expectancy, effort expectancy, social influence, and facilitating conditions are direct determinants of usage intention and behavior. Gender, age, experience, and voluntariness of use are posited to moderate the impact of the four key constructs on usage intention and behavior" (Venkatesh et al. 2003). The proposed model (see Fig. 1), extended the UTAUT model by adding two constructs, that is, competitive advantage and cost effectives, and one moderator variable org. type. Moreover, some related literature show that acceptance is technology could also be determined by cost effectiveness and competitive advantages. Hence, this research model employed a new combined model based on the UTAUT and related literature.

The UTAUT model consists of constructs that determine behavioral intention such as (1) performance expectancy, which is "degree to which an individual believes that using the system will help him or her to attain gains in job performance" (Venkatesh et al. 2003; Calisir and Calisir 2004); (2) effort expectancy, which is "the degree of ease associated with the use of the system" (Venkatesh et al. 2003); (3) social influence, which is "the degree to which an individual perceives that important others believe he or she should use the new system" (Venkatesh et al. 2003); (4) facilitating conditions, which is "the degree to which an individual believes that an organizational and technical infrastructure exists to support the use of the system" (Venkatesh et al. 2003); and (5) behavioral intention, which is "an individual's subjective probability that he or she will perform the behavior in question" (Venkatesh et al. 2003; AlAwadhi and Morris 2008). Based on Venkatesh et al. (2003) model, two moderator variables such as experience and voluntariness are included. Moreover, there are additional constructs that this research work

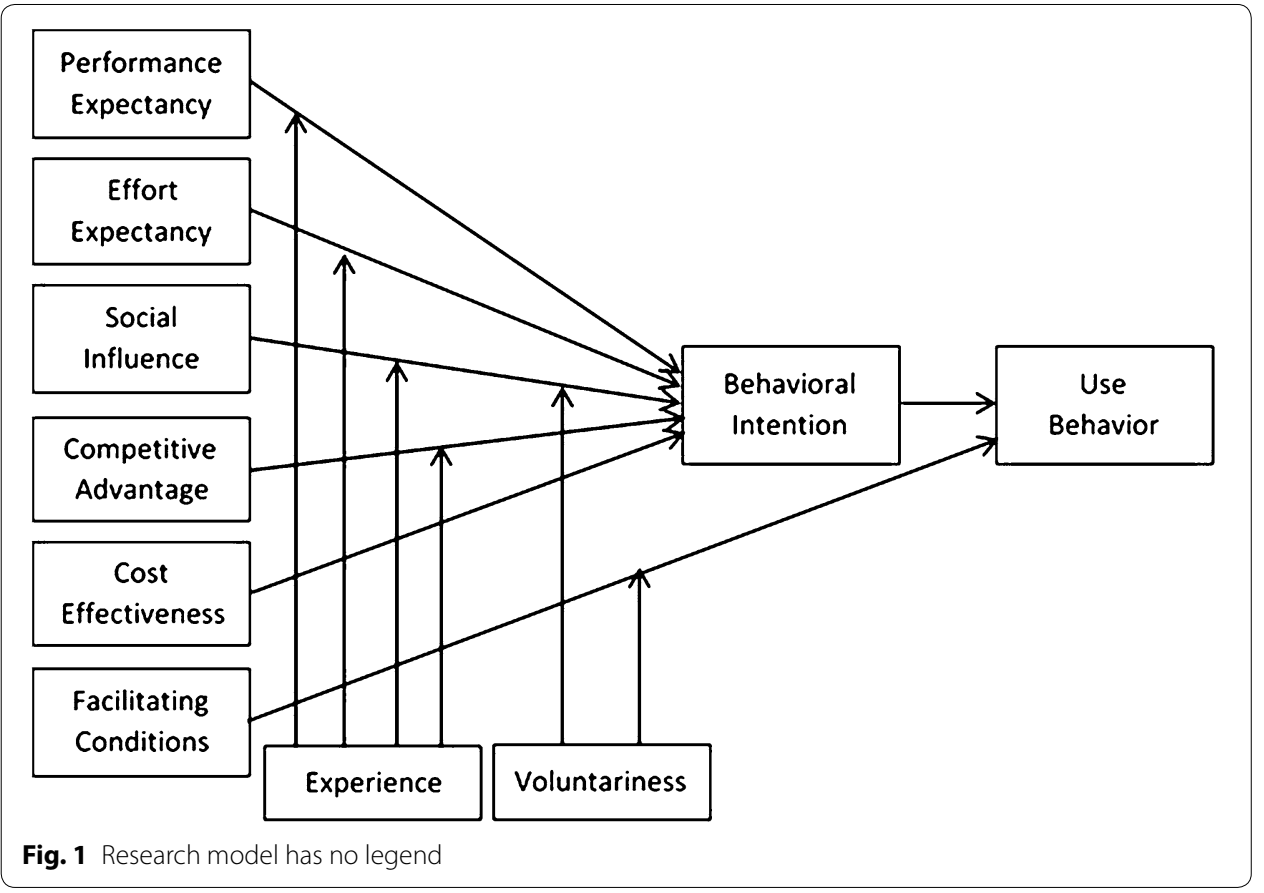


included on the UTAUT mode includes (6) competitive advantage, which is "the degree to which customers believe that using a particular new technology would enhance their competitive advantage in the market" (Ramesh 2011); (Moghavvemi et al. 2012); and (7) cost effectiveness, which is "the degree to which customers believe that the cost of a new technology desired to be adopted is affordable and it deserves for the intended service" (Ramesh 2011); (Moghavvemi et al. 2012); (Pantano and Di Pietro 2012).

This study consists of the following hypotheses:

H1 Behavioral intention to use homegrown ERP systems increases as organizations' performance expectancy increases, and this association is moderated by experience.

H2 There would be significant positive association between effort expectancy and behavioral intention to use homegrown ERP systems, and this association would be moderated by experience.

H3 Social influence would positively affect organizations' behavioral intention to use homegrown ERP systems, and this association would be moderated by experience and voluntariness.

H4 Competitive advantage of homegrown ERP systems would positively affect their behavioral intention to use, and this association would be moderated by experience.

H5 There would be significant positive association between cost effectiveness and behavioral intention to use homegrown ERP systems.

H6 Homegrown ERP system use behavior of organizations would positively be affected by their behavioral intention.

H7 Homegrown ERP system facilitating conditions would positively affect use behaviors of organizations, and this association would be moderated voluntariness.

\section{Methods}

This study employed quantitative empirical study through surveying organizations that are currently using homegrown ERP systems in Ethiopia. Structured questionnaire is used for gathering data from participants found in public and private business organizations, universities, and research centers which such systems are being utilized in. The questionnaire is administered to 351 research participants that include managers, programmers, designers, and end users of the system. The questionnaire consisted of 23 questions, in a 5-Likert scale ranging from 1 "strongly disagree" to 5 "strongly agree", that come out of the seven constructs of the research model. Participants were asked their voluntary participation before the questionnaire was distributed using consent forms and orally.

Constructs and statements were adopted from UTAUT model and related works and customized to fit the research context. Additional statements on the additional two 
constructs were added. From the distributed questionnaires, 324 were filled out and returned back, yielding a response rate of $92.3 \%$.

\section{Data analysis}

\section{Overview of respondents}

In this study, $76 \%$ of the respondents were male; most of them were between the age of 31 and 40 which accounts 38\%; 46\% of the respondents were BSc graduates followed by MSc graduates that is $24 \%$. The occupation of the respondents shows that managers $-17 \%$, programmers $-29 \%$, designers $-19 \%$, and end users $-35 \%$. About $38 \%$ of the respondents have 5-7 years of experience in using homegrown ERP systems, followed by $2-4$ years which accounts $28 \%$.

\section{Reliability and validity of the model}

Reliability of the study is measured by its Cronbach Alpha value. An acceptable measurement scale has to exceed a Cronbach Alpha value of 0.7 (Nunnaly 1978). The result of this study shows that all of the constructs had $\alpha>0.7$ which is acceptable and strong (See Table 1). Although the optimal value for composite reliability was 0.7 , results reported that all constructs exceeded 0.73 which showed strong reliability of the survey. Another measure of reliability to assess convergent validity was average variance extracted (AVE). AVE results should be greater than 0.5 which means fifty or more of the variance of the indicators should be accounted for (Fornell and Larcker 1981).

\section{Results}

To test those hypothesized statements of this study, the Pearson product-moment correlation coefficient ( $r$ ) was employed. According to Kothari (2004) "amongst the measures of relationship, Karl Pearson's coefficient of correlation is the frequently used measure in case of statistics of variables". Based on Pearson's correlation analysis, if the value or $r$ exceeds 0.5 , it indicates significant association between variables.

This empirical study analyzed seven hypotheses between factors that determine acceptance of homegrown ERP in Ethiopia. Consequently, all hypotheses showed positive association between the factors at a significance value of 0.01 . The first hypothesis (H1) states that there would be a significant positive association between performance expectancy (PE) and behavioral intention (BI) to use homegrown ERP systems, and this

Table 1 Psychometric properties of the survey scale

\begin{tabular}{lllllll}
\hline Construct & Items & Comp reliability & AVE & Alpha & Mean & Std. dev \\
\hline PE & 5 & 0.84 & 0.65 & 0.74 & 3.29 & 1.27 \\
EE & 7 & 0.75 & 0.73 & 0.81 & 3.30 & 1.40 \\
SI & 3 & 0.80 & 0.78 & 0.72 & 2.98 & 1.35 \\
CA & 6 & 0.73 & 0.69 & 0.79 & 3.03 & 1.34 \\
CE & 4 & 0.86 & 0.64 & 0.85 & 3.93 & 1.37 \\
FC & 6 & 0.78 & 0.81 & 0.75 & 3.60 & 1.47 \\
BI & 3 & 0.79 & 0.74 & 0.78 & 4.22 & 1.27 \\
\hline
\end{tabular}

$P E$ performance expectancy, EE effort expectancy, $S /$ social influence, $C A$ competitive advantage, $C E$ cost effectiveness, $F C$ facilitating conditions, $B /$ behavioral intention 
association is moderated by experience. The correlation coefficient between these two variables is $r=0.803$ at $p<0.05$, which depicts strong positive correlation. The second hypothesis $(\mathrm{H} 2)$ states that there would be significant positive association between effort expectancy (EE) and behavioral intention (BI) to use homegrown ERP systems, and this association would be moderated by experience. The correlation coefficient between these two variables is $r=0.738$ at $p<0.05$, which depicts positive correlation. The third hypothesis (H3) states that there would be a significant positive association between social influence (SI) and behavioral intention to use homegrown ERP systems and behavioral intention (BI) to use homegrown ERP systems, and this association would be moderated by experience and voluntariness. The correlation coefficient between these two variables is $r=0.829$ at $p<0.05$, which depicts positive correlation. The fourth hypothesis (H4) states that there would be significant positive association between competitive advantage (CA) and behavioral intention (BI) to use homegrown ERP systems, and this association would be moderated by experience. The correlation coefficient between these two variables is $r=0.849$ at $p<0.05$, which depicts strong positive correlation. The fifth hypothesis (H5) states that there would be significant positive association between cost effectiveness (CE) and behavioral intention (BI) to use homegrown ERP systems. The correlation coefficient between these two variables is $r=0.761$ at $p<0.05$, which depicts positive correlation. The sixth hypothesis (H6) states that there would be significant positive association between behavioral intention (BI) and use behavior (UB) of homegrown ERP systems. The correlation coefficient between these two variables is $r=0.780$ at $p<0.05$, which depicts positive correlation. The last hypothesis (H7) states that there would be significant positive association between facilitating conditions (FC) and use behavior (UB) of homegrown ERP systems, and this association would be moderated by voluntariness. The correlation coefficient between these two variables is $r=0.710$ at $p<0.05$, which depicts positive correlation.

In order to determine the predictors and their standardized weights of behavioral intention (BI) and use behavior (UB) of homegrown ERP, multiple regression analysis is computed between the dependent and independent variables (See Eq. 1).

$$
\gamma=\alpha+\beta_{1} X_{1}+\beta_{2} X_{2}+\cdots+\beta_{n} X_{n}+\varepsilon
$$

where: $\gamma=$ variable to be predicted or dependent variable (DV), $X=$ variable that predicts $\gamma, \alpha=$ intercept, $\beta=$ coefficient of $X, \varepsilon=$ regression residual (error).

As shown in Table 2, two regression analyses were carried out. The first regression was done between the independent variables that includes performance expectancy (PE),

Table 2 Results of multiple linear regression

\begin{tabular}{llllllr}
\hline Hypotheses & Path & $\boldsymbol{R}^{\mathbf{2}}$ & $\boldsymbol{F}$ & Std. error & $\boldsymbol{\beta}$ & $\boldsymbol{t}$ \\
\hline $\mathrm{H} 1$ & & & 0.045 & 0.244 & 7.27 \\
$\mathrm{H} 2$ & $\mathrm{PE} \rightarrow \mathrm{Bl}$ & & 0.027 & 0.151 & 5.08 \\
$\mathrm{H} 3$ & $\mathrm{EE} \rightarrow \mathrm{Bl}$ & & \multirow{2}{*}{411.3} & 0.058 & 0.141 & 2.27 \\
$\mathrm{H} 4$ & $\mathrm{SI} \rightarrow \mathrm{Bl}$ & 0.864 & & 0.060 & 0.312 & 4.87 \\
$\mathrm{H} 5$ & $\mathrm{CA} \rightarrow \mathrm{Bl}$ & & & 0.029 & 0.232 & 7.47 \\
$\mathrm{H} 6$ & $\mathrm{CE} \rightarrow \mathrm{Bl}$ & & & 0.040 & 0.555 & 15.13 \\
$\mathrm{H7}$ & $\mathrm{BI} \rightarrow \mathrm{UB}$ & 0.709 & \multirow{2}{*}{393.6} & 0.034 & 0.392 & 10.69 \\
\hline
\end{tabular}


effort expectancy (EE), social influence (SI), competitive advantage (CA) and cost effectiveness (CE), and the dependent variable behavioral intention (BI) (See Eq. 2). Moreover, use behavior (UB) is also determined by behavioral intention (BI) and facilitating conditions (FC) (See Eq. 3).

$$
\begin{aligned}
B I= & (-0.063)+(0.244 \times P E)+(0.151 \times E E)+(0.141 \times S I) \\
& +(0.321 \times C A)+(0.232 \times C E)+0.32 \\
U B= & 0.018+(0.555 \times B I)+(0.392 \times F C)+0.23
\end{aligned}
$$

The proportion of the variance in the dependent variable that is predictable from the independent variable is measured by the coefficient of determination $\left(R^{2}\right)$ (Stattrek 2016). If a regression model has greater explanatory power, its coefficient of determination will be high. Hence, in this study, the value of $R^{2}$ for behavioral intention (BI) is 0.864 , meaning that $86.4 \%$ of the variance in behavioral intention is explained by this regression model. Besides, this high value of $\left(R^{2}\right)$ shows that the regression model is very good, and the model is statistically significant at $F=411.3$, confidence interval $95 \%$, and $p<0.001$. Figure 2 shows determination weights of the independent variables on behavioral intention in the first regression analysis.

The second regression was done between the independent variables that includes behavioral intention (BI) and facilitating conditions (FC), and the dependent variable use behavior (UB). The value of $\mathrm{R}^{2}$ for use behavioral (UB) is 0.709 , meaning that $70.9 \%$ of the variance in use behavioral is explained by this regression model. Besides, this high value of $\left(R^{2}\right)$ shows that the regression model is very good, and the model is statistically significant at $F=393.6$, confidence interval 95\%, and $p<0.001$. Figure 3 shows determination weights of the independent variables on behavioral intention in the first regression analysis.

\section{Discussion}

The empirical demonstration of the modified UTAUT model was able to distinguish constructs that determine the intention and use of homegrown ERP systems along with the effects of moderators on the association between the predictors and the outcomes.

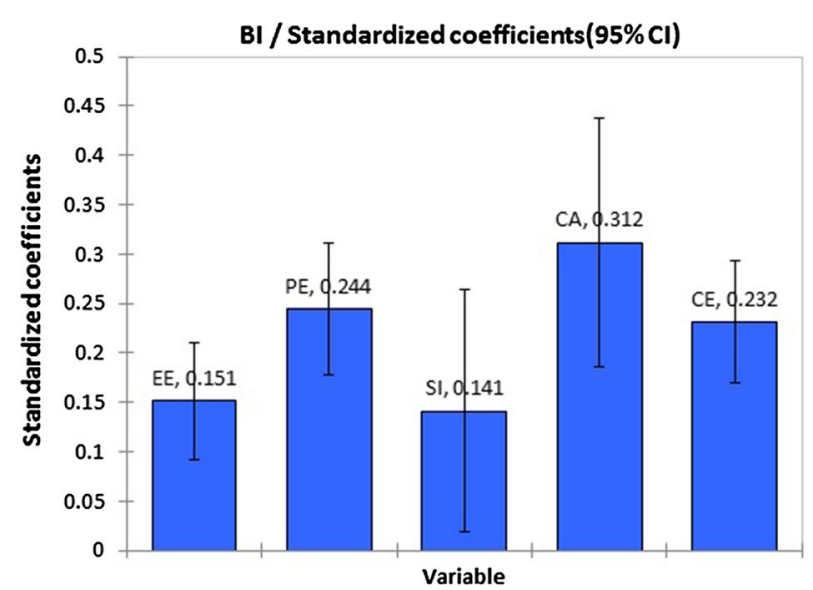

Fig. 2 Coefficients of regression analysis (Phase 1) variables (PE, EE, SI, CA and CE) 


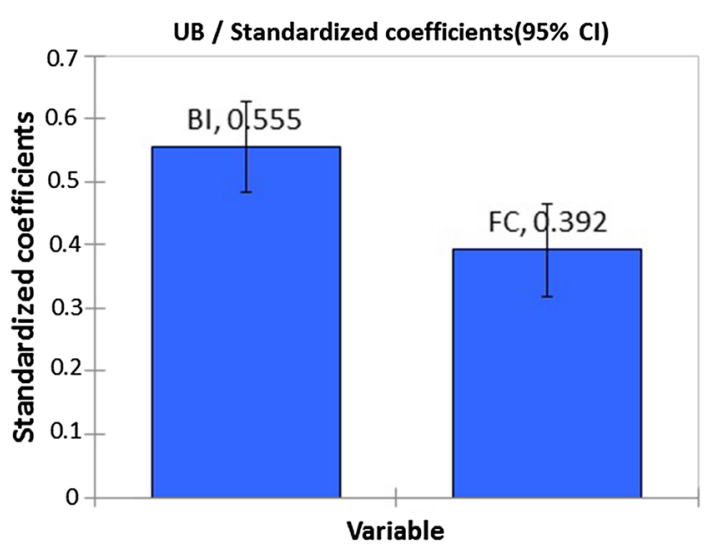

Fig. 3 Coefficients of regression analysis (Phase 2) variables (BI and FC)

The impact of performance expectancy on respondents' behavioral intention was significant. However, when its value increased when it was moderated by experience. This shows that organizations that have better experience on software use relate their benefits with the use of homegrown ERP systems. The association between effort expectancy and behavioral intentions of research participants. The association was moderated by the participants' experience on such systems. The result suggested that users are interested to use homegrown ERP systems when such systems are easy to use enabling them to have more time for other activities. The result was found to be higher on experienced users. The finding disclosed that social influence was significant to the participants' behavioral intention only for those who had less experience and voluntariness. This suggests that social influence becomes more significant when people have limited experience. The relationship between competitive advantage and behavioral intention of respondents was significant. This suggests that users' behavioral intention to use homegrown ERP increases if they believe that the system will have competitive advantage. Moreover, experienced users showed greater understanding on the competitive advantage of such software. There was significant positive association between cost effectiveness and behavioral intention of respondents. This shows that users' need on such systems reduces as its price increases. Cost effective homegrown ERP systems are more preferable than their counter parts. Both facilitating conditions and behavioral intention were found to be significant for use of homegrown ERP systems. Besides, for behavioral intention to use such systems, voluntariness is found to be significant moderator. This in turn depicts that if users get the required resources, information and continuous support, they will be motivated to use systems that go with their life preferences.

\section{Implications and conclusions}

This empirical study identified those factors that determine acceptance of homegrown ERP in Ethiopia through an extended UTAUT model. The findings showed that performance expectancy, effort expectancy, social influence, competitive advantage, cost effectiveness and facilitating conditions were significant in acceptance of homegrown ERP in Ethiopia. This in turn shows that the findings could be applicable to other developing countries whose context is similar to Ethiopia. The model acceptance or adoption 
model homegrown ERP by user subjects was well predicted using performance expectancy, effort expectancy, social influence, competitive advantage, cost effectiveness and facilitating conditions, and the moderating effects of experience and voluntariness. The model developed in this study has made a foundation for future research works that focus on adoption of homegrown ERP systems in the context of developing countries. Future research could focus on, for example, integration of homegrown ERP and COTS and its risk.

Decision makers on the adoption and use of homegrown ERP systems have to understand these adoption determinants in order to be benefited from their advantages over COTS. Benefits include this software could specifically be designed per the requirements of organizations and can be tailored to fit exactly with the way the organization inquires; such software is flexible and can be customized to interface with other software as well; it is possible to easily access support services that commonly emanate from changing rules, regulations and requirements.

\section{Acknowledgements}

First and foremost, my sincerest appreciation and gratitude goes to research respondents for their patience and time spent on the questionnaire. My gratitude go to Bahir Dar University too for its ambitious plan and encouragement of researchers to engage themselves in research carriers. Finally, I would like to dedicate this research work to my family for their love, encouragement, patience and unconditional support.

\section{Competing interests}

The author declare that he has no competing interests.

Received: 8 January 2017 Accepted: 3 March 2017

Published online: 14 March 2017

\section{References}

AlAwadhi S, Morris A (2008, January) The Use of the UTAUT model in the adoption of E-GOVERNMENT services in Kuwait. In Hawaii international conference on system sciences, Proceedings of the 41 st annual. IEEE, pp 219

Bingi P, Sharma M, Godla J (1999) Critical issues affecting an ERP implementation. Inf Syst Manag 16:7-14

Calisir F, Calisir F (2004) The relation of interface usability characteristics, perceived usefulness, and perceived ease of use to end-user satisfaction with enterprise resource planning (ERP) systems. Comput Hum Behav 20(4):505-515

Ehie IC, Madsen M (2005) Identifying critical issues in enterprise resource planning (ERP) implementation. Comput Ind 56(6):545-557

Fornell C, Larcker DF (1981) Evaluating structural equation models with unobservable variables and measurement error. J Market Res 18:39-50

Heald K, Kelly J (1998) AMR research predicts ERP Market Reach \$52 Billion by 2002

Kien SS, Soh C (2003) An exploratory analysis of the sources and nature of misfits in ERP implementations. In Secondwave enterprise resource planning systems

Kothari CR (2004) Research methodology: methods and techniques. New Age International, New Delhi

Lucas HC Jr, Walton EJ, Ginzberg MJ (1988) Implementing packaged software. MIS Quart 12:537-549

Markus ML, Cornelius T (2000) The enterprise systems experience-from adoption to success. In: Zmud RW (ed) Framing the domains of IT research: glimpsing the future through the past. Pinnaflex Educational Resources, Cincinnati

Moghavvemi S, Hakimian F, Feissal T, Faziharudean TM (2012) Competitive advantages through IT innovation adoption by SMEs. Soc Technol 2(1):24-39

Nunnaly JC (1978) Psychometric theory, 2nd edn. New York, MCGraw-Hill

Pantano E, Di Pietro L (2012) Understanding consumer's acceptance of technology-based innovations in retailing. J Technol Manag Innov 7(4):1-19

Rajagopal P (2002) An innovation — diffusion view of implementation of enterprise resource planning (ERP) systems and development of a research model. Inf Manag 40(2):87-114

Ramesh HN (2011) Competitive advantage and Employee's attitude towards IT intervention. Int I Contemp Bus Stud 2(6):42-52

Soh C, Kien SS, Tay-Yap J (2000) Enterprise resource planning: cultural fits and misfits: is ERP a universal solution? Commun ACM 43(4):47-51

Statistica (2016) Global ERP software revenue 2011-2016 | Statistic https://www.statista.com/statistics/247557/ global-erp-software-revenue/

Stattrek (2016) Linear regression. 2016. Linear regression. http://stattrek.com/regression/linear-regression.aspx. Accessed 10 Nov 2016 
Stratman JK, Roth AV (2002) Enterprise resource planning (ERP) competence constructs: two-stage multi-item scale development and validation. Decis Sci 33(4):601-628

Umble EJ, Haft RR, Umble MM (2003) Enterprise resource planning: implementation procedures and critical success factors. Eur J Oper Res 146(2):241-257

Venkatesh V, Morris MG, Davis GB, Davis FD (2003) User acceptance of information technology: toward a unified view. MIS Quart 1:425-478

AlQashami A, Heba M (2015) Critical success factors (CSFs) of enterprise resource planning (ERP) system implementation in Higher Education Institutions (HEls): concepts and literature review. In: Zizka J, Nagamalai D (eds) Computer science \& information technology, fourth international conference on advanced information technologies and applications (ICAITA 2015). Dubai, UAE, pp 81-98

Zhelyazkov GI (2012) The impact of ICT systems on road transport SMEs in Australia

Submit your manuscript to a SpringerOpen ${ }^{\circ}$ journal and benefit from:

- Convenient online submission

\section{- Rigorous peer review}

- Immediate publication on acceptance

- Open access: articles freely available online

- High visibility within the field

- Retaining the copyright to your article

Submit your next manuscript at $\boldsymbol{\nabla}$ springeropen.com 